\title{
Comparative Study of Supporting Services for Children with Down's syndrome and Their Families: Perspective of United Kingdom and Bangladesh
}

\author{
Mahmudul Hasan ${ }^{1}$ and Mohammad Kamrujjaman ${ }^{2 *}$ \\ ${ }^{1}$ Deputy Manager-Disability, Inclusion and Rehabilitation, Disabled Rehabilitation and Research Association (DRRA), Bangladesh \\ ${ }^{2}$ Lecturer of Physiotherapy, State College of Health Sciences, Bangladesh
}

*Corresponding author: Mohammad Kamrujjaman, Lecturer of Physiotherapy, State

College of Health Sciences, Dhaka, Bangladesh.

Received Date: March 17, 2019

Published Date: April 04, 2019

\begin{abstract}
Background: A comparative study of supporting services which are available in United Kingdom and Bangladesh for the children with Down syndrome (DS) and their families were explored in the present research by doing literature review based on documentary research methodology.
\end{abstract}

Purpose: The aim of the study was to identify the gaps, discrepancies, merits and demerits between these two countries service providers for the children with DS and their families.

Methods: Bangladesh and United Kingdom were selected for the literature review. The literatures were collected from many sources such as websites, international or national organizations, public and private organization's published report, provision and strategies, e-books, journals, articles and books. The Literatures reviewed were key sources of evidence to justify findings. Gaps, discrepancies have also been found in the Government and private sector providing services.

Discussion: There are some similarities, merits and demerits have also identified by exploring services which are available in United Kingdom and Bangladesh for proving services for the children with DS and their families. Some recommendations have been suggested for the authority who deals with the children with DS and their families.

Conclusion: It has been stated that except accessible roads, schools and transportation for the children with DS, without trained and enough professionals and staffs who can deal with DS children and their families properly, and improper management among stakeholders can make very challenging for DS children and their families to get proper services.

Keywords: Down syndrome; Literature review; Supporting services; Public \& private organization

\section{Introduction}

Down syndrome (DS) is a genetic condition that results in some level of learning disability and a particular range of physical characteristics. Learning disability can affect a person to learn very new things into their every aspect of their life including at school [1]. Therefore, children with DS can have difficulty in learning new things, understanding information, communicating properly, confronting a complex situation, and/ or coping independently. In addition of learning disabilities, children with DS may have various kinds of health-related problems such as CHD (Congenital Heart Disease), vision problems, hearing loss, infections, hypothyroidism, blood disorders, poor muscle tone, sleep disorders, gum or dental problems, epilepsy, digestive problems, mental and emotional problems, and so on [2]. Hence, a different type of supporting services like educational, emotional, financial, recreational rather than medical services is needed for dealing with DS children. DS can be detected from mother's womb to after birth. There are many screening programmes which can be carried out during pregnancy. During this screening programme, every mother should get proper guidelines and idea about what to do if the outcome is positive or negative. Education can be provided to the children with DS either at special school or mainstream school according to the 
parent's desire or the present condition of that child. As children with DS have associated health problems as well as they require special care, their parent's may face financial problem to look after them. Therefore, children with DS require supporting services from being their mother's womb till lifelong. United Kingdom is a country of $63,136,000$ populations. Among them, almost 60,000 people are living with DS as every year one in every 1000 babies are born with this condition [3]. Unfortunately, Bangladesh does not have studies to say how many people are suffering from the chromosomal disorder like a DS. But some organizations who work with children with DS has estimated that about 200,000 individuals are suffering from DS in Bangladesh, this estimation has been made based on the global trend that one in every 800 children born with this chromosomal abnormality though. The children with DS begin to get their services from a different type of health care providing institutions as prenatal screening and diagnostic test. Supporting health care services can be public funded and/ or private hospital, clinic, and diagnostic centre. As the prenatal screening or diagnostic test is to be done on the pregnant woman, therefore proper, realistic, unprejudiced knowledge about the test should be provided to them before going to test. Thus, prenatal screening and diagnostic test is related to health care providing institutions, health care providers, professionals and services provided information about test and DS, and government policies. Therefore, this study will be looked at all the services regarding prenatal and diagnostic test both in UK and Bangladesh in order to compare their services. Mother of a child with DS may face various problems when she noticed that she has given birth a child with DS. Yildirim et al. [4] state that this situation exposes mothers to intense stress and emotional problems such as denial, anxiety, anger, guilt, unexpected crisis, avoidance of facing external world's attitude, disappointment, decrease in selfconfidence and self-respect. As individuals with DS have associated medical problems, so referral and getting access to specialized professionals according to their problems need to be done. Supporting services may take useful steps to do this. Specialized education and interventions can greatly benefit children with DS [5]. All children place a financial burden upon their parents because of their special needs for therapy, toy, medical procedures, and additional care. Except for financial supporting services, it may be difficult for a nation without universal health care systems in order to raise a child with DS. The research will explore the services for the children with DS and their families which are provided by the both UK and Bangladesh in order to get a comparison study. By exploring the services, the research will be looked at the gaps, advantages, disadvantages, similarities between these two countries' services and trying to find out the potential reasons which are lie to know the present condition of the supporting services which are mostly used and accessed by the children with DS ages from 0 to 18 years and their families.

\section{Literature Review}

\section{Pre-natal diagnosis for down syndrome}

Prenatal diagnosis can be done in two ways- one is called prenatal screening test and another is a prenatal diagnostic test [6].
In 2001, the UK National Screening Committee recommended that all pregnant mothers are offered to screen for DS [7]. Some studies $[8,9]$ have concluded that due to lack of proper knowledge about screening can make a pregnant woman to make decisions for either invasive testing or termination. Midwives, GP, paediatricians can provide information about screening, test, and its outcome. The study, which was conducted by the Hwa et al. [10] concluded that trained counsellors improved the women's knowledge about the test and encouraged informed choice. Nagle et al. [11] concluded that detailed information about specific testing could increase the knowledge and satisfaction of pregnant women. Unfortunately, Bangladesh does not have any provision for prenatal screening as well as test for detecting DS antenatal. Bangladesh government has just started a pilot project in 2012 for detecting the number of an individual is being disabled [12]. Therefore, services like health institutions (public or private or charity) and its staff (Midwives, Doctor, Nurses, Healthcare Assistants and so on), and public or electronics media could take part in spreading knowledge to the society, particularly to the pregnant women about DS and its outcome and what they should do after getting a baby with DS.

\section{Post-natal diagnosis and support}

The children with Down syndrome can be diagnosed immediately after birth by observing some distinctive features on baby's countenance [13]. Children are usually under the care of a paediatrician from birth, who will screen for heart defects and watch out for any other health risks known to be associated with Down syndrome [14]. DS child may be checked more often than other children to pick up developing problems as early as possible [1]. In the UK, health visitors visit every new born baby's house routinely to observe baby's developmental progress. According to babies' development, they provide essential information to the parents. Children with DS shows weaning problems, delayed teething, dry skin, temperature control abnormality, sleep problems, unable to hold breast and improper toileting [15]. More than 70 percent of the population in Bangladesh currently lives in rural areas [16]. However, the Bangladesh Government and Non-government organizations are trying to strengthen the public health sector by taking some initiatives. It must be recognized that Bangladesh has a well-structured health system with three tiers of primary health care as Upazila Health Complexes (UHC) at the sub-district level, Union Health and Family Welfare Centres (UHFWC) at the Union (collection of few villages) level, and Community Clinics (CC) at the village level and these are backed by the District Hospitals providing secondary level care and the tertiary hospitals of various kind in large urban centres [17]. In addition, Shishu Bikash Kendra (Child Development Centres) has been established in district hospitals and these centres in government tertiary medical colleges perform early assessment and diagnosis for children identified with potential disabilities including DS and they also treat disabilities and offer training and support for parents which are now located in 10 government medical hospitals, 3 in Dhaka and 7 outside and also plans call for replication in all 17 government hospitals and 20 district hospitals [18]. 


\section{Emotional support}

All the mothers having a child with DS had shown a negative reaction about their child's condition and made them shocked and fearful. Although several participants described the various resources and emotional support like support from medical staff, parents of DS children, charity organizations were significant for the coping of adjustment process with DS children [19]. The Down's syndrome Association in UK provide all kinds of emotional support to the parents of DS children. 'Contact a Family for a Disabled Child' is another charity organization that provides emotional support to the parents of DS children. There are many regional DS groups in the UK which provide emotional support to the parents of DS children [14]. In contrast to UK, there is no either public or private emotional support service in Bangladesh which could potentially provide emotional support to the disabled children or their families. Although, there is one centre named Shishu Bikash Kendra (Child Development Centres) situated in some government tertiary medical colleges which provide some sort of emotional support and training to the parents who have a disabled child including DS [18]. Beside this, there are some NGO's provide emotional support to the parents, for example; Handicap Bangladesh, Muslim Aid etc. Due to lack of emotional support, people with disability and their family believe that it is their fate and disabled children are inferior to able-bodied children and disabled children do not have right to participate in any socio-cultural activities [17]. As a consequence, the family may keep their disabled children away from society and sometimes disabled children considered as family's burden as they are unable to earn money for their family. In Bangladesh, a survey conducted in rural areas shows that emotional problem was the most embarrassing problem where 50\% respondents stated that they are hated and avoided by the well-bodied peoples as a consequence about $50.4 \%$ respondents don't participate in any community activities [17].

\section{Referral to the specialist professionals}

Specialist professionals (Cardiologist, Endocrinologist, Physiotherapist, Occupational therapist, Speech therapist, Psychologist, Educator, etc.) are necessary for children with DS in order to deal with their problems as they show many problems. In the UK, every person has got a family doctor called as General Practitioner (GP) with free of cost [6]. The However, general practitioner is responsible for dealing with children's daily health issues and health visitors visit family homes in the early years to check on children's health and development. They provide help, advice and practical assistance about the care of very young children, child development, sleep patterns, feeding, behaviour and safety [20]. Paediatrician usually refers a DS child to ear, nose and throat consultant (ENT consultant), audiologist, cardiologist/ cardiac surgeon, neurologist, ophthalmologist, endocrinologist, gastroenterologist, oncologist, physiotherapist (PT), occupational therapist (OT), speech and language therapist (SALT). PT, OT and SLT provide essential support, advice and information to the parents as well as to the children at home or at hospital or clinics and the rest of the specialists which mentioned above are usually provide necessary support at the hospital [20]. In Bangladesh, specialized rehabilitation services for disabled children are provided by the Government under the direction of the Ministry of Social Welfare (MOSW) and by non-government organizations (NGOs) [18]. "Hope for Life", "Muslim Aid Bangladesh", "Centre for Rehabilitation of the Paralysed' are some of the known NGO's working with disabled children in Bangladesh to provide the rehabilitation services like physiotherapy, occupational therapy, speech therapy. Jatiyo Protibondhi Unnayan Foundation (JPUF) has established 68 onestop service centres in 64 districts by the favour of Ministry of Social welfare and the World Bank for the children with disabilities to provide essential advice, physiotherapy, occupational or speech therapy, assistive device, mobility or hearing or vision aids and referral to specialist professionals with free of cost [21].

\section{Education for children with down syndrome}

Weakness and strength of DS children in the educational context: One major difficulty of most children with DS demonstrate is in language development. Laws \& Bishop [22] reported that the language abilities of children with DS were significantly compromised in comparison to their non-verbal cognitive level. Rosner et al. [23] compared the social competence of individuals aged 4 to 49 with DS, Prader-Willi syndrome or Williams' syndrome. Nevertheless, when compared to their typically developing peers, children with Down syndrome are typically more likely to demonstrate behavioural difficulties, such as non-compliance and stubbornness [24]. Therefore, proper educational strategies, intervention, and skilled teachers and supporting staff can educate a child with DS.

Inclusive education for children with DS: Successful inclusive schools describe the crucial significance of parents' participation in the process of their child's inclusive education. Baker et al. [25] indicate from three meta-analyses that a small-to-moderate positive effect of inclusive education exists in terms of social and academic outcomes for children with special needs. Research has found that learners with learning difficulties who attended inclusive classrooms did not show high levels of loneliness and that a remarkable increase was evident in the number of reciprocal relationships that they formed [26,27]. In the UK, the Code of Practice defines the essential framework of Government guidance on the treatment of children with special educational needs. Department for Education and Department of Health [28] has set out a number of 'fundamental principles' in the Code of Practice. In the UK, LA's responsible for SEN services that provide support for children in the family home, at nurseries and playgroups and in a range of school settings. There is virtually no access to preschool education in Bangladesh for children with disabilities, except for programs designed and implemented through non-governmental organizations. For example, BRAC and Save the Children's have run a project since 1997 known as preschools or early childhood programs that serve children with disabilities. These programs has been serving to children at the "pre-primary" level, which includes children ages 5 to 6 or 7 years of age [29]. 


\section{Financial support for children with DS}

Existing studies indicate that mother's possibility to work outside at home may be decreased if she has a disabled or sick child $[30,31]$ and father's work hours can be reduced due to looking after a disabled child Therefore, financial support either from government or charity or private organization can be helpful for the parents having a Down syndrome child in order to meet their child demands as well as they can provide enough time to look after their children. In the UK, a wide range of financial assistance is available for the parents of a disabled child including Down syndrome and anyone can be eligible to have those aids. The Department for Work and Pensions (DWP) in UK is responsible for providing all types of benefit. Anyone can claim for getting Disability Living Allowance (DLA) if he has a child under-16 with disability [32]. DLA is a tax free benefit which is usually paid every 4 weeks. The rate DLA is made up of 2 components (parts) namely; care component and mobility component. The weekly rate varies from $£ 21.80$ to $£ 82.30$ depends on how disability or health condition affects one's daily life. In addition, if anyone needs financial help in order to meet their essential needs then they can contact with the financial advisors of Down Syndrome Association, which is a charitable organization works for the welfare of the family and children with DS. On the other hand, Bangladesh government provides allowance only to an insolvent person with disability. This allowance programme has been started from 2004-2005 budget sessions with 24.99cores BDTK [33]. This budget has now reached to 240.00 cores BDTK in 2014 - 2015. An individual with disability would get 200 BDTK per month in the beginning of this allowance programme which was in 2004-2005 session. Now it has increased to 500 BDTK per month for a person [12].

\section{Social support for children with DS and their families}

Dunst et al. [34] defined social support as being a multidimensional construct that includes physical and instrumental assistance, sharing of information and resources, and as providing emotional and psychological support. Therefore, the summation of these above definitions provided the definition of social support as emotional, psychological, financial, institutional, informational support which can come from family members, friends, teachers, any public or private institutions, and professional states. In the UK, local authorities (LA) provide essential support, advice and help to the disabled children and their parents in order to meet their needs [20]. Parents or disabled children do not even need to do register to get the support from LA. It is a programme which is arranged in a way by which children with disability can develop their personal and social progress as well as parents can get some rest from their caring responsibilities [35]. Social workers can provide practical help, advice, information and support to get access into the supporting services for all disabled children or their parents or even whose do not have internet access or unable to browse or unaware of 'local offers'. Apart from those public social supporting services, the UK has a lot of private or charitable organizations which provide social support both to the parents and disabled children. 'Contact a Family' runs a helpline for family members and parents to get in touch with other parent carers of disabled children living nearby [36].

\section{Methodology}

Bangladesh and United Kingdom were selected for the literature review. The literature review was the main source to justify the following research questions. These are:

a. What health services are available for children with DS?

b. Is there any emotional support service receivable by the parents having children with DS?

c. Is there any educational service for educating children with DS?

d. What financial support is available for the children with DS and their families?

The literatures were collected from many sources such as websites, international or national organizations, public and private organization's published report, provision and strategies, e-books, journals, articles and books. It is a social science research method refers to the analysis of documents that contain information about the phenomenon one wish to study [37]. Here, phenomenon refers to the services existing both in Bangladesh and UK to provide support for the children with DS and their families. Documents present a good source of text data [38]. The literatures related to DS children aged from 0-18 years and their families were selected for review. The literatures were mainly collected from two countries - Bangladesh and United Kingdom in order to answer the research questions as this research doing a comparison of services providing by these two countries for the children with DS and their families. A number of computer and electronic sources were used to identify studies relevant to the research questions. These included Willey Online Library, PubMed, Google Search, Google Scholars, Government websites, International and National organization's website, Non-government organization's website, Private and charity institution's website. Beside electronic database, manual searching of literature were used to answer the research questions. Ethical consideration is very important for undertaking a social research. Therefore, ethical approval for this present research had to be sought and gained from the University of South Wales Faculty of life Sciences and Education Research Committee. The author also has checked that all the documents had sought for ethical approval. It is sometimes assumed that secondary or documentary analysis of data raises a few or no ethical considerations. However, therefore the researcher will be reliant on the consent that is being gained on the literatures.

\section{Findings}

The principal purpose of this present research was to compare the services which are provided by the both UK and Bangladesh for the children with DS and their families. The present research has also identified some potential reasons which may help to better understand the services and supports most needed and accessed by the children with DS and their families. These are described below: 


\section{Government provisions and services}

In the UK, the National Screening Committee advises ministers and the NHS of four UK countries about all aspects of screening and supports the implementation of screening programmes including DS screening [39]. The purpose of this screening is to offer all women a screening test for DS and to provide information so that they are able to exercise informed choice. Having this opportunity provided by the UK Government, all the pregnant women in this country can make an independent choice about their proceeding pregnancy, whether to considers termination or planning for the welfare of their child. This Government provision increases knowledge and understanding of the UK pregnant women about DS than the Bangladeshi pregnant women who are completely unaware of the DS condition. The public running school for disabled children are very limited as well as there is virtually no access to pre-school education in Bangladesh for disabled children. Only two Government schools for intellectually disabled children are obviously not enough for educating the entire disabled children including DS. Lack of enough public funded educational institutions, deficiency of inclusive educational settings is the main problem in getting proper education of the DS children in Bangladesh. However, the amount is good enough to meet the daily expenses of an individual as it varies from $£ 21.80$ to $£ 82.30$ weekly [32]. Whereas in Bangladesh, Government allowance is only given to the insolvent disabled individual. If any disabled children belong to a solvent family then he will not be eligible to get this allowance in Bangladesh. The allowance is only 500 BDTK per month (500 BDTK= 6.43 USD) which is too less for maintaining living expenses in anywhere in Bangladesh. Although, the allowance has increased from 200BDTK to 500 BDTK per month [12] but it is still not enough. Therefore, Bangladesh Government needs to focus on raising the public fund regarding disabled children and their families. In contrast to $\mathrm{UK}$, there is no public organization or agency in Bangladesh for providing any kind of social support. Having no social support, the family often sees the disabled children as a burden [18] as well as most of the disabled children are socially isolated and anxious about their disability [17]. Therefore, deficiency of Government provision concerned with social support, recruitment of social worker and joined up working among different stakeholders are identified as the gap between these two countries regarding to social support.

\section{Private or charity or non-government organization's services}

There are a lot of charity organizations in the UK, which deal with the DS children and their families. Some of these charity organizations either work with the DS children or their families. These charity organizations are mainly run by the donation. These charity organizations have a lot of branches and a lot of workers all over the UK. They provide information, support, services, and advice from the birth of a disabled child till their entire lives. Unlike UK, the NGO in Bangladesh provide services to the disabled children after their born. There are no public services concerned with specific emotional support in the UK. However, private or charity organizations are playing the main role of providing emotional support to the parents of DS children in UK. The parents of a disabled child in UK can easily contact another parent having a child with disability through the charity organizations websites or phone call and can share their feelings, experience, emotions. Apart from this, these organizations have special advisors for providing emotional support through consultancy with free of cost. Here, literacy and availability of internet offer them to get access into these sources easily and quickly. Unfortunately, there are no services either public or private which could provide emotional support to the parents of a disabled child in Bangladesh. Due to lack of emotional support, the parents of a disabled child make them socially isolated, often see their disabled children as their burden and even it may lead parent's separation [17]. There are 40 schools (units/branches) that provide special education and vocational training and other programs for children with intellectual disabilities, in addition to the National Institute for the Intellectually Disabled (NIID) and the BRAC schools. It is clear that Bangladesh Government does not have any authorised agency or body as LA's in UK which can monitor all the school activities and also transparent that NGO's are the main providers in Bangladesh for educating the disabled children, unlike UK. Most of the charity organization has a financial advisor who provides essential information to the parents of disabled children in order to get proper and accurate financial support from the Government. Anyone can get social support from any charity organizations either with the help of social workers or by phone call or doing registration over the internet. Compared to UK, Bangladesh has some namely financial support providing NGO's. There is even no social support providing service except one that is situated in the capital of Bangladesh.

\section{Trained professionals and staff}

A major problem is the lack of skilled and trained personnel to support inclusive practices and training in behaviour and classroom management techniques in Bangladesh. Obstacles include low job satisfaction for primary school teachers due to poor salaries and high student-teacher ratios, high numbers of staff vacancies, rising workloads, low levels of awareness about disability and sensitivity to children with disabilities, limited technical support for inclusive education, and lack of monitoring to ensure policies are carried out [18]. The shortage of trained professionals and staff has also seen as a problem in the health sector of Bangladesh. Bangladesh Health Watch has concluded that Bangladesh suffers from shortages and misdistribution of staff, a skill mix imbalance, a negative work environment and a weak knowledge base all of which impact the availability and quality of health services received by children with disabilities [40]. Qualified practitioners constitute a low percentage of all health care providers and the country lacks sufficient numbers of doctors, nurses and health technologists according to WHO standards and averages for low-income countries [41]. Unlike Bangladesh, the UK has 2.8 physicians per 1000 people [42] as well as total expenditure on health per capita (Intl \$, 2013) is 3,311 [3]. These statistics confirmed that the UK Government spends too much money behind the health sector including training of health sector professionals and staffs regularly. 


\section{Literacy and usage of internet}

Stromquist [42] states that literacy skills are fundamental to informed decision-making, personal empowerment, active and passive participation in the local and global social community. These statistics show that almost half of the population in Bangladesh cannot read and write. Due to a lack of empirical support, it is not possible to estimate the exact number of literate parents having children with disabilities. It is assumed that about half of the families with disabled children are not literate; therefore almost half of the population does not know about their rights and responsibility which they supposed to have from Government and other sectors. This statistic also shows that most of the people in the UK have access to the internet. For this reason, every Government and charity organizations provide every kind of information about their services through their websites. Therefore, children with DS and their families can get any kind information whether it is related to health, education, finance, emotional and social support from the internet very easily and quickly. Unlike UK, internet usage by the population 15 years and over has showed that only $1.49 \%$ used internet at the national level, and the corresponding figures were $2.00 \%$ for males and $0.97 \%$ for females while in the rural areas, only $1.13 \%$ used internet $(1.52 \%$ males and $0.73 \%$ females) compared to $2.61 \%, 3.50 \%$ and $1.72 \%$ for both gender in the urban areas [43]. If any Bangladeshi service providing agency would provide their information through the internet then it would not probably be reached to the entire population whether or not related to disabilities. Therefore, Bangladesh Government should take a step to provide education in all areas as well as further study should be carried out to recognize the proper media in order to provide information about DS.

\section{Management and co-ordination}

Management and coordination mechanisms have been established at different levels to support planning, monitoring and cooperation within the Bangladesh Government and among NGOs and parents [18] Whereas in the UK, Section 25 of the Children and Families Act 2014 places a duty on local authorities that should ensure integration between educational provision and training provision, health and social care provision, where this would promote wellbeing and improve the quality of provision for disabled young people and those with SEN [28]. Furthermore, under the Section 26 of the Act, the Local authorities and clinical commissioning groups (CCGs) must make joint commissioning arrangements for education, health and care provision for children and young people with SEN or disabilities. Therefore, only one governing body as LA's are responsible for ensuring that there is effective coordination and management among all the sectors. The Bangladesh Government could overcome from their management and coordination problem if they had only one governing body which would deal with the disability-related all sectors as UK has LA.

\section{Access to services}

Lack of accessibility is to be a major barrier to use of services which are available for children with disabilities in Bangladesh
Public transportation also presents barriers to accessing services and schools, especially for wheelchair users who cannot ride buses and trains independently. An Infrastructural barrier is also one of the key obstacles for the inclusion of children with disabilities in education. Lack of accessible toilets also forces many children to drop out of school, especially girls. Leonard Cheshire Disability [44] states that It has been noted that in many cases in developing countries like Bangladesh, disabled children especially girl children do not go to school since they are unable to use the toilet facilities. Infrastructural accessibility in the school buildings and overall accessible environment is required for children with disabilities. When there are no access roads, and transportation then it becomes very challenging for a child with disability and their families to get proper services in Bangladesh. On the other hand, all the services in the UK related to health, education, finance, emotional and social support for children with DS and their families are easy to get access. The children with DS and their families do not often need to go to the hospitals or rehabilitation centres for getting proper health services as health visitors monitor the developmental progress of a child at a regular basis in the UK. Finance, emotional and social service can also get easily by the parents with DS children with the help of the social worker who is available in every location of the UK. The Government of Bangladesh has introduced some initiatives to improve the situation concerned with disability; for example, Executive Order from the Office of the Prime Minister, 2002 highlighted a number of activities to reduce barriers to public transportation, The 2010 Education Policy addresses inclusion of children with disabilities, and the Comprehensive Early Childhood Care and Development [45].

\section{Conclusion}

It has found that there are many gaps between these two countries public service providers for children with DS and their families. A lack of Government provision, insufficient health service centres, transportation of babies to get proper health services, lack of enough public funded educational institutions, deficiency of inclusive educational settings, shortage of public funds, deficiency of Government provision concerned with social support, and recruitment of social worker were identified as the main gap which are lying between these two countries. Lack of trained staffs and teachers has found as another gap between these two countries schools concerned with DS children. Although, Bangladesh has less trained SEN professionals and staffs in every sector, unlike UK. Bangladesh is far away from UK in term of literacy and usage of the internet. Illiteracy and lack of using internet has made Bangladeshi populations especially children with DS and their families unaware about DS and its outcome and uncertain about existence of services available for them. Lack of accessibility is another major barrier to use of services which are available for children with disabilities in Bangladesh. Many schools, hospitals, rehabilitation centres, Government offices are not accessible to children with disabilities due to the location. Therefore, public transportation is the only way to get access to those organizations. Due to high transportation cost, poor families are unable to afford. In addition, the infrastructures of schools are not disabled friendly in Bangladesh, unlike UK. Almost 
all the schools are disabled friendly in the UK and most often the children with DS and their families do not need to go around for getting proper services from different stakeholders. When there are no access roads, schools and transportation, trained and enough professionals and staffs, and proper management among stakeholders then it becomes very challenging for children with Down syndrome and their families to get proper services in Bangladesh.

\section{Conflict of Interest}

Authors of the article declare that there is no conflict of interest regarding this article.

\section{Acknowledgement}

'We are the authors acknowledge the support provided by the faculty of life sciences \& education, University of South Wales \& State college of Health Sciences, Dhaka, Bangladesh.

\section{Disclosure of Benefits}

No funding was received for this work from any organization.

\section{Concerned Documents}

\begin{tabular}{|c|c|c|}
\hline Investigated Area & $\begin{array}{l}\text { UK Concerned } \\
\text { Documents }\end{array}$ & $\begin{array}{l}\text { Bangladeshi Concerned } \\
\text { Documents }\end{array}$ \\
\hline $\begin{array}{l}\text { Pre-natal Diagnosis } \\
\text { for Down's } \\
\text { syndrome }\end{array}$ & $\begin{array}{l}\text { Gammons et al. } \\
\text { (2010), } \\
\text { NHS choice UK (2014), } \\
\text { Rowe et al. (2006), } \\
\text { Seror \& Ville (2009), } \\
\text { Hwa et al. (2010), } \\
\text { Nagle et al. (2008). }\end{array}$ & $\begin{array}{l}\text { Ministry of Social } \\
\text { Welfare (2015). }\end{array}$ \\
\hline $\begin{array}{l}\text { Post-natal } \\
\text { Diagnosis and } \\
\text { Support }\end{array}$ & $\begin{array}{c}\text { Down's syndrome } \\
\text { Association (2015), } \\
\text { Early Support (2010), } \\
\text { NHS choice. Down } \\
\text { syndrome (2015), } \\
\text { Bull (2011). }\end{array}$ & $\begin{array}{c}\text { Unicef (2014), } \\
\text { Ahmmad and Islam } \\
\text { (2014). }\end{array}$ \\
\hline Emotional Support & $\begin{array}{c}\text { Regional Down's } \\
\text { syndrome Groups in } \\
\text { the UK, } \\
\text { Early Support (2012), } \\
\text { Joosa and Berthelsen } \\
\text { (2006), } \\
\text { Down's syndrome } \\
\text { Association (2015). }\end{array}$ & $\begin{array}{c}\text { Unicef (2014), } \\
\text { Ahmmad and Islam } \\
\text { (2014). }\end{array}$ \\
\hline $\begin{array}{l}\text { Referral to } \\
\text { the Specialist } \\
\text { Professionals }\end{array}$ & $\begin{array}{l}\text { NHS choice UK (2014), } \\
\text { Early Support (2012). }\end{array}$ & $\begin{array}{l}\text { Unicef (2014), } \\
\text { Ministry of Social } \\
\text { Welfare (2015). }\end{array}$ \\
\hline $\begin{array}{l}\text { Education For } \\
\text { the Children with } \\
\text { Down syndrome }\end{array}$ & $\begin{array}{c}\text { Department for } \\
\text { Education and } \\
\text { Department of Health } \\
\text { (2015), } \\
\text { Laws and Bishop } \\
\text { (2003), } \\
\text { Rosner et al. (2004), } \\
\text { Dykens et al. (2002), } \\
\text { Baker et al. (1995) } \\
\text { LeRoy \& Simpson } \\
\text { (1996), } \\
\text { Vaughn et al. (1996) }\end{array}$ & USAID (2005). \\
\hline
\end{tabular}

\begin{tabular}{|c|c|c|}
\hline $\begin{array}{c}\text { Financial Support } \\
\text { for Children with } \\
\text { DS and their } \\
\text { Families }\end{array}$ & $\begin{array}{c}\text { Disability Living } \\
\text { Allowance for Children } \\
(2015), \\
\text { Powers (2001), } \\
\text { Corman et al. (2005), } \\
\text { Early Support (2010). }\end{array}$ & $\begin{array}{c}\text { Ministry of Social } \\
\text { Welfare (2015), } \\
\text { The Department of } \\
\text { Social Services under } \\
\text { the Ministry of Social } \\
\text { Welfare (2013). }\end{array}$ \\
\hline & $\begin{array}{c}\text { Early Support (2012), } \\
\text { Essex County Council } \\
(2014),\end{array}$ & \\
$\begin{array}{c}\text { Social Support for } \\
\text { Children with DS } \\
\text { and their Families }\end{array}$ & $\begin{array}{c}\text { Contact a family } \\
(2012),\end{array}$ \\
& $\begin{array}{c}\text { Down's syndrome } \\
\text { Association (2015), } \\
\text { Dunst et al. (1986a). }\end{array}$ & \\
& & \\
&
\end{tabular}

\section{References}

1. NHS choice (2015) Down syndrome.

2. National Institute of Health in USA (2014) NIH: What conditions or disorders are commonly associated with Down syndrome?

3. World Health Organization (2015) World Health Organizations: United Kingdom. WHO, Geneva, Switzerland.

4. Yildirim SH, Bas BZ (2010) Depression among mothers of children and adults with an intellectual dis-ability in Turkey. Int J Nurs Pract 16(3): 248-253.

5. Marshall J, Tanner JP, Kozyr YA, Kirby RS (2014) Services and Supports for Young Children with Down Syndrome: parenst and providers perspectives. Child Care Health Dev 41(3): 365-373.

6. NHS choice UK (2014)

7. Gammons S, Sooben DJ, Heslam S (2010) Support and Information about Down's syndrome. British Journal of Midwifery 18(11): 700-708.

8. Rowe HJ, Fisher JRW, Quinlivan JA (2006) Are pregnant Australian women well informed about prenatal genetic screening? A systematic investigation using the Multidimensional Measure of Informed Choice. Aust NZ J Obstet Gynaecol 46(5): 433-439.

9. Seror V and Ville Y (2009) Prenatal screening for Down syndrome: women's involvement in decision-making and their attitudes to screening. Prenat Diagn 29(2): 120-128.

10. Hwa HL, Huang LH, Hsieh FJ, Chow SN (2010) Informed consent for antenatal serum screening for Down syndrome. Taiwan J Obstet Gynecol 49(1): 50-56.

11. Nagle C, Gunn J, Bell R, Lewis S, Meiser B, et al. (2008) Use of a decision aid for prenatal testing of fetal abnormalities to improve women's informed decision making: a cluster randomised controlled trial [ISRCTN22532458]. BJOG 115(3): 339-347.

12. Ministry of Social Welfare (2015) The Allowance for Insolvent Disabled Individual (In Bengali).

13. Bull MJ, Committee on Genetics (2011) Health Supervision for Children with Down syndrome. Paediatrics 128(2): 393-406.

14. Down's syndrome Association (2015) Training and Support Services.

15. Early Support (2010) UK government published booklet. Helping Every Child Succeed: Information for Parents Down syndrome.

16. The World Bank (2013) The World Bank: Data Physicians (per 1000 people).

17. Ahmmad RM, Islam NM (2014) Impact of Disability on Quality of Life of Urban Disabled People in Bangladesh. International Journal of u-and e-Service, Science and Technology 7(4): 227-238.

18. Unicef (2014) Situation Analysis on Children with Disabilities in Bangladesh.

19. Joosa E, Berthelsen D (2006) Parenting a child with Down syndrome: A phenomenographic study. Journal on Developmental Disabilities 12(1S2): 45-58. 
20. Early Support (2012) UK government published booklet. Helping Every Child Succeed: Information for Parents Down syndrome.

21. Ministry of Social Welfare (2015) The disabled help and Service Centre.

22. Laws G, Bishop DVM (2003) The comparison of language abilities in adolescents with Down syndrome and children with specific language impairment. J Speech Lang Hear Res 46(6): 1324-1339.

23. Rosner BA, Hodapp RM, Fidler DJ, Sagun JN, \& Dykens EM (2004) Social competence in persons with Prader-Willi, Williams and Down's syndrome. Journal of Applied Research in Intellectual Disabilities 17(3): 209-217.

24. Dykens EM, Shah B, Sagu, J, Beck, T, King BH (2002) Maladaptive behaviour in children and adolescents with Down's syndrome. J Intellect Disabil Res 46(6): 484-492.

25. Baker ET, Wang MC, Walberg HJ (1995) The effects of inclusion on learning. Educational Leadership 52(4): 33-35.

26. LeRoy B, Simpson C (1996) Improving student outcomes through inclusive education. Support for Learning 11(1): 32-36.

27. Vaughn S, Elbaum BE, Schumm JS (1996) The effects of inclusion on the social functioning of students with learning disabilities. J Learn Disabil 29(6): $598-608$.

28. Department for Education and Department of Health (2015) Special educational needs and disability code of practice: 0 to 25 years. Statutory guidance for organisations which work with and support children and young people who have special educational needs or disabilities.

29. USAID (2005) Assessment of Educational Needs of Disabled Children in Bangladesh.

30. Powers ET (2001) Children's Health and Maternal Work activity: static and dynamic estimates under alternative disability definitions. Journal of Human Resources 38: 522-556.

31. Corman H, Noonan K, Reichman NE (2005) Mothers' and Fathers Labour Supply in Fragile Families: the role of the child. Eastern Economics Journal 31: 601-616.
32. Disability Living Allowance for Children (2015).

33. The Department of Social Services under the Ministry of Social Welfare (2013) A Review of Implementation Manual for the Allowance Programme of Insolvent Persons with Disabilities.

34. Dunst CJ, Trivette CM, Cross AH (1986a) Mediating influences of social support: Personal, family and child outcomes. Am J Ment Defic 90(4): 403-417.

35. Essex County Council (2014) Support for Disabled Children and Young People and their Families in Essex: Guidance for working together with disabled children, young people and families to provide early help, targeted and specialist support.

36. Contact a family (2012) Contact a family: for Families with disabled Children.

37. Mogalakwe M (2006) The Use of Documentary Research Methods in Social Science. African Sociological Review 10(1): 221-230.

38. Creswell JW (2008) Educational Research: planning, conducting, and evaluating Quantitative and Qualitative Research. Prentice Hall, USA

39. UK National Screening Committee (2015) UK National Screening Committee.

40. Bangladesh Health Watch Report (2011) Bangladesh Health Watch Report: Moving towards Universal Health Coverage 2011.

41. Uincef (2013) Unicef, Bangladesh: Statistics.

42. Leonard Cheshire Disability. Barriers to Education 2010: a Note Book.

43. Stromquist, NP (2005) The political benefits of adult literacy, Norwich: Paper commissioned for the EFA Global Monitoring Report. Literacy for Life.

44. Bangladesh Bureau of Statictis. Report on the Bangladesh Literacy Survey 2010.

45. Early Support (2013) UK government published booklet. Helping Every Child Succeed: Information for Parents Down syndrome. 